\title{
Synthesis and Properties of a Double-sided and Multi-layered Metal Organic Framework
}

\author{
Huanqing Ma , Shujun Wang*, Hongyan Liu, Fanbin Meng, Weiying Gao, \\ Xingyu $\mathrm{Xu}$.
}

State Key Laboratory of Heavy Oil Processing, China University of Petroleum (Beijing), Beijing 102249, China.

E-mail: mahuanqinggg@163.com; bjwsjbj@sina.com

Corresponding Author: Shujun Wang

\begin{abstract}
Keywords: Metal organic frameworks, double-sided and multi-layered, multifunctional materials carboxylate ligands, coordination polymers, gas sorption.
\end{abstract}

\begin{abstract}
Two new double-sided and multi-layered network porous compound named 1 $\left[\mathrm{Ni}_{2}(\mathrm{BTC})_{2}(\mathrm{DABCO})(\mathrm{DEA})_{2}\right]$ have been synthesized by solvent thermal synthesis method. Which, for the first time, exhibit an unusual double-sided and multi-layered MOF. The double-sided MOF structure extended to regular hexagon morphology in accordance with schematic representation of the $2 \mathrm{D}$ topological net of $\mathbf{1}$ and also confirmed by the SEM images. The $\mathrm{N}_{2}$ and $\mathrm{H}_{2}$ sorption certified it can be used as gas absorption.
\end{abstract}

\section{Introduction}

Porous metal-organic frameworks (MOFs) also known as porous coordination polymers, are crystalline coordination networks consisting of metal ions/clusters and organic linkers, are currently under intensive investigation because of their rich structural chemistry and outstanding properties, regarding not only the specific surface area and storage capacities, but also the flexibility of the framework. $^{[1-3]}$ The systematic design and construction of coordination polymers by using organic molecular building blocks and metal ions appeared in the early half of the 1990s, More than 20000 MOF structures have been reported and studied since then. In 1999, two archetypical MOFs, MOF-5 $\left(\mathrm{Zn}_{4} \mathrm{O}(\mathrm{bdc})_{3}\right.$, bdc=terephthalate $) \quad$ and HKUST-1( $\mathrm{Cu}_{3}(\mathrm{btc})_{2}$, btc $=1,3,5$-benzenetricarboxylate $)^{[4,5]}$ were synthesized and characterized, symbolizing a benchmark in MOF chemistry with their high porosity indicated by crystal structures and confirmed by low pressure gas sorption studies.

A key structure feature of MOFs is the ultrahigh porosity (up to $90 \%$ free volume) and incredibly high internal surface areas, extending beyond a Langmuir surface area of $10000 \mathrm{~m}^{2} \mathrm{~g}^{-1}$, which play a crucial role in functional applications, typically in storage and separation, ${ }^{[6]}$ sensing, ${ }^{[7]}$ proton conduction $^{[8]}$ and drug delivery. ${ }^{[9]}$ One of the most interesting features of MOFs is that frequently their structure can be deduced from the directionality of organic linkers and the coordination geometry of metal building blocks. In this way, MOFs can be engineered to a large extent and can be synthesized by design with the desired structure and dimension. In this regard, we have constructed a new Two-Dimensional multi-layered Network porous compound named 1 $\left[\mathrm{Ni}_{2}(\mathrm{BTC})_{2}(\mathrm{DABCO})(\mathrm{DEA})_{2}\right]$, (Nickel nitrate hexahydrate $\mathrm{H}_{3}$ btc=1,3,5-benzenetricarboxylate acid(Bridge ligand), DABCO=1,4-diazabicyclo[2.2.2]octane ( Auxiliary ligand ) , DEA =Diethylamine) by using rigidly designed carboxylate ligands in solvent thermal synthesis method, which, for the first time, exhibit an unusual double-sided and multi-layered MOF. The $\mathrm{N}_{2}$ sorption isotherms show that it has a large Brunauer-Emmett-Teller (BET) surface area and pore volume. In its structure, $\mathrm{Ni}$ atoms to adopt irregular quadrilateral double-heap coordination model. Every $\mathrm{Ni}$ atoms coordinated with four $\mathrm{O}$ atoms(two come from one bivalent carboxylic group of one btc, (two $\mathrm{O}$ atoms are in mono dentate coordination come from two monobasic carboxylate $\mathrm{O}$ ions of two btc ligand in a planar separately ) , the two pairs of $\mathrm{O}$ atoms form a square-planar coordination around 
the $\mathrm{Ni}$ atom (Figure 1. a)). DABCO as bridging ligands, which act as pillars to extend the double-sided 2D layers (Figure 1. b)). The DABCO pillar molecules, which occupy the axial positions of the $\left[\mathrm{Ni}_{2}(\mathrm{BTC})_{2}(\mathrm{DABCO})(\mathrm{DEA})_{2}\right]$ paddle-wheels, the double-sided 2D layers structure further interconnect and extend into a multi-layered architecture by Van der Waals force and H-bond interaction(Figure 1. e)). Two $\mathrm{N}$ atoms axially coordinated to one Ni come from DABCO and DEA. The four $\mathrm{O}$ atoms form a planar coordinated around the central $\mathrm{Ni}$ atom, Axis of N-Ni-Ni-N perpendicular to the planar, the six $\mathrm{Ni}$ atoms build up a isosceles triangular prism constructure. The bonds length of Ni-O are $2.1873 \AA$ and $2.0594 \AA$, The bonds length Ni-N are $2.0913 \AA$ and $2.1811 \AA$ separately. The Ni...Ni distance connected by a ligand DABCO are of $6.9590 \AA$.

a)

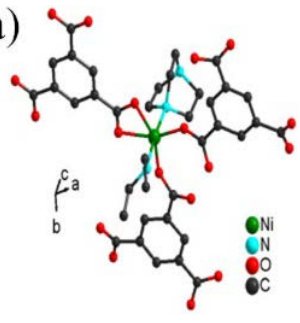

b)

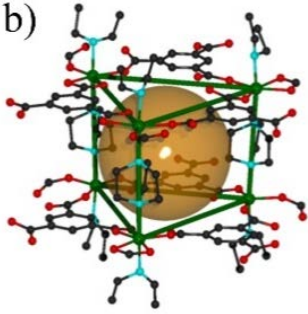

e)

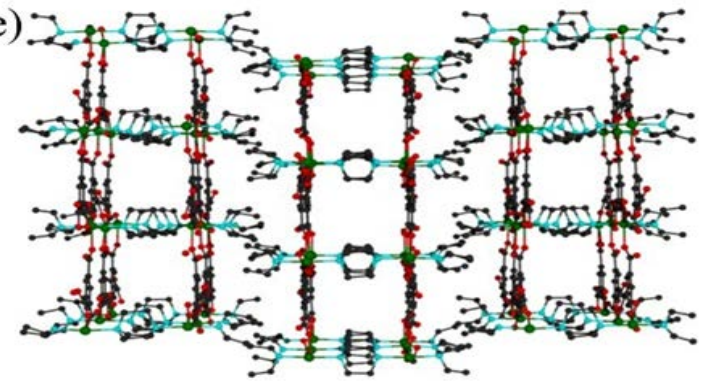

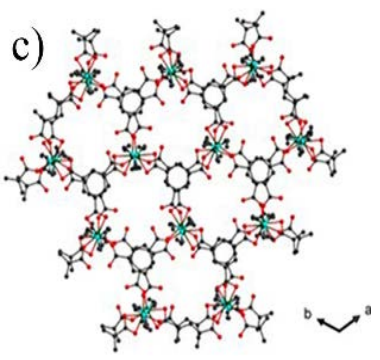

d)

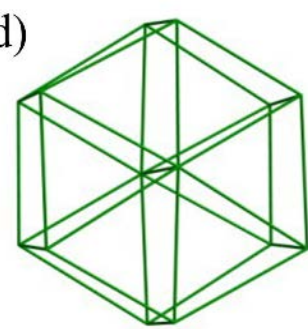

f)

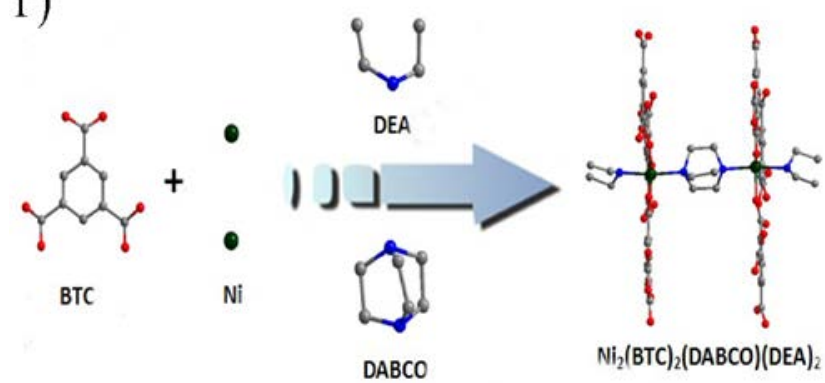

Figure 1. a) the coordination modes of six-connected $\mathrm{Ni}_{2}(\mathrm{BTC})_{2}$ (DABCO)(DEA) 2 SBUs; b) a isosceles triangular prism in 1; c) View of the porous framework of 1 viewed close to [100] direction; d) schematic representation of the 2D topological net of 1 (viewed close to the [100] direction; green connection point representing the dummy node of triangle plane(three $\mathrm{Ni}$ ) of a isosceles triangular prism; e) View of the multi-layered porous framework of $\mathbf{1}$ viewed close to [010] direction; f) Schematic representation of the formation of $\mathrm{Ni}_{2}(\mathrm{BTC})_{2}(\mathrm{DABCO})(\mathrm{DEA})_{2}$.

\section{Experimental Section.}

Chemicals were purchased from commercial sources and used without further purification. Powder X-ray diffraction (PXRD) was carried out with an X-ray diffractometer of Rigaku, Rint 2000. $\mathrm{C}, \mathrm{H}$, and $\mathrm{N}$ elemental analyses were conducted on a Perkin-Elmer 240C elemental analyzer. Thermo gravimetric analyses (TGA) were carried out on a Perkin-Elmer TG-7 analyzer heated from room temperature to $873 \mathrm{~K}$ at a ramp rate of $5 \mathrm{~K} / \mathrm{min}^{-1}$ under nitrogen. The $\mathrm{N}_{2}$ and $\mathrm{H}_{2}$ sorption measurements were performed on automatic volumetric adsorption equipment (Belsorp mini II ). Before gas adsorption measurements, the sample was treated with ethanol and dichloromethane. Before the measurement, the sample was dried again by using the "outgas" function of the surface area analyzer for $12 \mathrm{~h}$ at $393 \mathrm{~K}$.

The data were collected by using graphite-monochromatized enhanced ultra Cu radiation at $293 \mathrm{~K}$. The data sets were corrected for empirical absorption correction by using spherical harmonics, as implemented in the SCALE3 ABSPACK scaling algorithm. The structures of the compound $\mathbf{1}$ were solved by direct methods ${ }^{[10]}$ and refined by full-matrix, ${ }^{[11]}$ least-square methods with the SHELX-97 program package. Determinations of the unit cells and data collection for crystal of $\mathbf{1}$ were performed on an Oxford Xcalibur Gemini Ultra diffractometer with an Atlas detector ${ }^{[12]}$. The solvent molecules in the compound are highly disordered, and the SQUEEZE ${ }^{[13]}$ subroutine of the PLATON $^{[14]}$ software suite was used to remove the scattering from the highly disordered guest 
molecules. The resulting new files were used to further refine the structures. The $\mathrm{H}$ atoms on $\mathrm{C}$ atoms were generated geometrically. ${ }^{15]}$

Crystal data for $\mathrm{Ni}_{2}(\mathrm{BTC})_{2}$ (DABCO)(DEA) 2 : $\mathrm{T}=293 \mathrm{~K}$, empirical formula $=\mathrm{Ni}_{2} \mathrm{C}_{32} \mathrm{H}_{34} \mathrm{O}_{12} \mathrm{~N}_{4}$, cryst syst=trigonal, $\mathrm{M}_{\mathrm{r}}=785.42$, $\mathrm{a}=17.00$ (3) $\AA, \mathrm{b}=17.00$ (3) $\AA, \mathrm{c}=30.00$ (3) $\AA, \alpha=90^{\circ}, \beta=90^{\circ}, \gamma=$ $120^{\circ}, \mathrm{V}=7508 \AA^{3}, \mathrm{Z}=1, \mathrm{D}_{\text {calc }}=0.793 \mathrm{~g} / \mathrm{cm}^{3}$, final $\mathrm{R} 1=0.0854$,

\section{Synthesis of the metal-organic framework Ni2(BTC)2(DABCO)(DEA)2.}

A typical preparation, a solid mixture of $\mathrm{H}_{3} \mathrm{BTC}\left(\mathrm{H}_{3} \mathrm{BTC}=1,3,5\right.$-benzenetricarboxylate acid(0.420 g, $2 \mathrm{mmol}$ ), DABCO (DABCO =1,4- diazabicyclo [2.2.2] octane (0.112 g, $1 \mathrm{mmol}$ ), DEA (DEA = Diethylamine, $0.128 \mathrm{~g}, 2 \mathrm{mmol}$ and $\mathrm{Ni}\left(\mathrm{NO}_{3}\right)_{2} \cdot 6 \mathrm{H}_{2} \mathrm{O}(0.580 \mathrm{~g}, 2 \mathrm{mmol})$ was dissolved in DEF $(\mathrm{DEF}=\mathrm{N}, \mathrm{N}$-Diethylformamide; $15 \mathrm{ml}$ ). The resulting solution would turn to limpid from cloudy suspension after drop concentrated nitric acid (at an approximate ratio of one drip every $10 \mathrm{ml}$ ), distributed among two $20 \mathrm{ml}$ vials. The vials were then heated at $100{ }^{\circ} \mathrm{C}$ in an isothermal oven for 72 h. After cooling the vials to room temperature, the green crystals product was isolated by decanting with the mother liquor and washed in DEF $(3 \times 3 \mathrm{ml})$ for 2 days. Solvent exchange was carried out with ethanol $(3 \times 10 \mathrm{ml})$ at room temperature for 2 days. The material was then evacuated under vacuum at $60{ }^{\circ} \mathrm{C}$ for $6 \mathrm{~h}$, yielding $0.495 \mathrm{~g}$ of $\mathrm{Ni}_{2}(\mathrm{BTC})_{2}$ (DABCO)(DEA) $)_{2}$ in the form of solid (63\% yield).

Elemental analysis: calcd(\%) for $\left[\mathrm{Ni}_{2}(\mathrm{BTC})_{2}(\mathrm{DABCO})(\mathrm{DEA})_{2}\right.$ : Ni, 14.9; O, 24.4; C, 48.9; H, 4.32; N, 7.1; found (\%):Ni, 14.8; O, 24.5; C, 49.2; H, 4.12; N, 7.2.
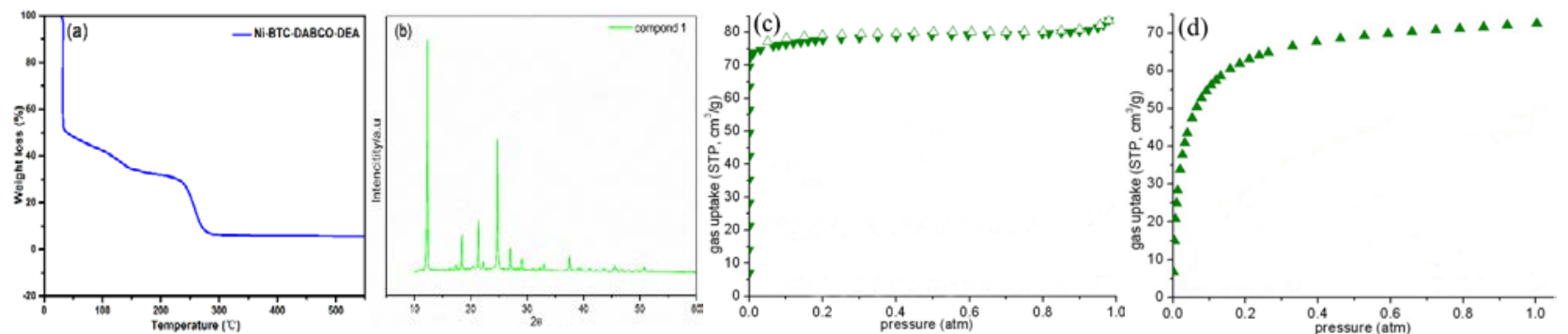

Figure 2. (a) The TGA curves of the compound 1; (b) XRD patterns of compound 1; (c)N2 sorption isotherms for compound 1 at $77 \mathrm{~K}$;(d) $\mathrm{H} 2$ sorption isotherms for 1 at $77 \mathrm{~K}$.

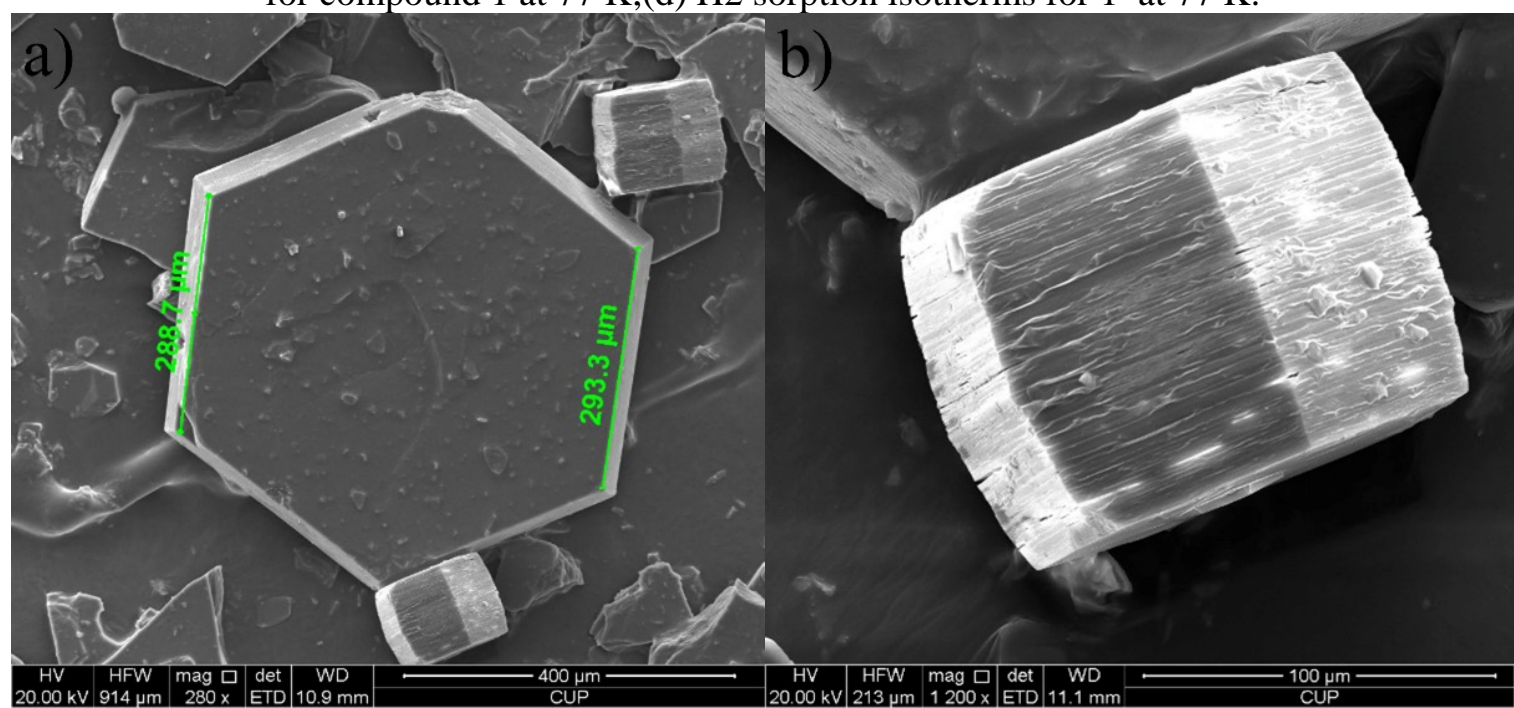

Figure 3. SEM images of the prepared Ni2(BTC)2(DABCO)(DEA)2: a) The regular hexagon picture of compound 1 ; b) The multi-layered picture of compound 1.

\section{Conclusions}

The present work shows a further example $\mathrm{Ni}_{2}(\mathrm{BTC})_{2}(\mathrm{DABCO})(\mathrm{DEA})_{2}$. Which exhibit an unusual double-sided and multi-layered MOF. The DABCO pillar molecules, which occupy the axial 
positions of the $\left[\mathrm{Ni}_{2}(\mathrm{BTC})_{2}(\mathrm{DABCO})(\mathrm{DEA})_{2}\right]$ paddle-wheels, the double-sided 2D layers structure further interconnect and extend into a multi-layered architecture by Van der Waals force and H-bond interaction. The double-sided MOF structure extended to regular hexagon morphology in accordance with schematic representation of the 2D topological net of $\mathbf{1}$ (Figure 1. (d)). That also confirmed by the SEM images of the prepared $\mathrm{Ni}_{2}(\mathrm{BTC})_{2}(\mathrm{DABCO})(\mathrm{DEA})_{2}$ (Figure 3.). The $\mathrm{N}_{2}$ sorption isotherm for 1 shows a typical external adsorption behavior at $77 \mathrm{~K}$. Giving maximum uptakes of $77.2 \mathrm{~cm}^{3} / \mathrm{g}$, he highest $\mathrm{H}_{2}$ uptake of $72.6 \mathrm{~cm}^{3} / \mathrm{g}$. The Langmuir surface areas are $2986 \mathrm{~m}^{2} / \mathrm{g}$, which smaller than and surface area $\left(3214 \mathrm{~m}^{2} / \mathrm{g}\right)$ calculated by Materials Studio 6.0 , the theoretical pore volume $(0.81$ $\mathrm{cm}^{3} / \mathrm{g}$ ) respectively and the density is $0.793 \mathrm{~g} / \mathrm{cm}^{3}$.

\section{Acknowledgements}

The authors gratefully thank the financial support of State Key Laboratory of Heavy Oil Processing in China University of Petroleum-Beijing.

\section{References}

[1] (a) C. D. Wu and W. Lin, Angew. Chem., Int. Ed., 2005, 44, 1958-1961; (b) X. Feng, X. Ding and D. Jiang, Chem. Soc. Rev., 2012, 41, 6010-6022; (c) Y. Q. Chen, G. R. Li, Z. Chang, Y. K. Qu, Y. H. Zhang and X. H. Bu, Chem. Sci., 2013, 4, 3678-3682; (d) Q. Chen, Z. Chang, W. C. Song, H. Song, H. B. Song, T. L. Hu and X. H. Bu, Angew. Chem., Int. Ed., 2013, 52, 11550-11553; (e) B. L. Chen, S. C. Xiang and G. D. Qian, Acc. Chem. Res., 2010, 43, 1115-1124.

[2] L. Ma, A. Jin, Z. Xie and W. Lin, Angew. Chem., Int. Ed.., 2009, 48, 9905-9908.

[3] J. Liu, B. Lukose, O. Shekhah, H. K. Arslan, P. Weidler, H. Gliemann, S. Brase, S. Grosjean, A. Godt, X. Feng, K. Mullen, I. B. Magdau, T. Heine and C. Woll, Sci. Rep., 2012, 2, 921, DOI: 10.1038/srep00921.

[4] A. P. Nelson, O. K. Farha, K. L. Mulfort and J. T. Hupp, J. Am. Chem. Soc., 2009, 131, 458-460.

[5] Y.-P. He, Y.-X. Tan and J. Zhang, Inorg. Chem., 2012, 51, 11232-11234.

[6] S. S.-Y. Chui, S. M.-F. Lo, J. P. H. Charmant, A. G. Orpen and I. D. Williams, Science, 1999, 283, 1148-1150.

[7] B. Chen, M. Eddaoudi, S. T. Hyde, M. O'Keeffe and O. M. Yaghi, Science, 2001, 291, 1021-1023.

[8] (a) X. Lin, I. Telepeni, A. J. Blake, A. Dailly, C. M. Brown, J. M. Simmons, M. Zoppi, G. S. Walker, K. M. Thomas, T. J. Mays, P. Hubberstey, N. R. Champness and M. Schroder, J. Am. Chem. Soc., 2009, 131, 2159-2171; (b) X. Lin, A. J. Blake, C. Wilson, X. Z. Sun, N. R. Champness, M. W. George, P. Hubberstey, R. Mokaya and M. Schroder, J. Am. Chem. Soc., 2006, 128, 10745-10753; (c) X. Chen, S. He, F. Chen and Y. Feng, CrystEngComm, 2014, 16, 8706-8709.

[9] (a) Y. Liu, W. Xuan, H. Zhang and Y. Cui, Inorg. Chem., 2009, 48, 10018-10023; (b) Y.-P. He, Y.-X. Tan, F. Wang, J. Zhang, Inorg. Chem., 2012, 51, 1995-1997; (c) X. L. Zhao, H. Y. He, F. N. Dai, D. F. Sun and Y. X. Ke, Inorg. Chem., 2010, 49, 8650-8652.

[10] A. L. Spek, J. Appl. Crystallogr., 2003, 36, 7-13.

[11] Y. X. Tan, Y. P. He and J. Zhang, Chem. Commun., 2011, 47, 10647-10649.

[12] B. Chen, S. Ma, E. J. Hurtado, E. B. Lobkovsky and H. C. Zhou, Inorg. Chem., 2007, 46, 8490-8492.

[13] Y. S. Bae, A. M. Spokoyny, O. K. Farha, R. Q. Snurr, J. T. Hupp and C. A. Mirkin, Chem. Commun., 2010, 46, 3478-3480. 
[14] C. Prestipino, L. Regli, J. G. Vitillo, F. Bonino, A. Damin, C. Lamberti, A. Zecchina, P. L. Solari, K. O. Kongshaug and S. Bordiga, Chem. Mater., 2006, 18, 1337-1346.

[15] S. Bourrelly, P. L. Llewellyn, C. Serre, F. Millange, T. Loiseau and G. Ferey, J. Am. Chem. Soc., 2005, 127, 13519-13521. 